\begin{tabular}{|c|c|c|}
\hline $\begin{array}{l}\text { EXCELLENT } \\
\text { PUBLISHERS } \\
\end{array}$ & $\begin{array}{c}\text { International Journal of Current Research } \\
\text { and Academic Review } \\
\text { ISSN: 2347-3215 (Online) :,; Volume 5:,; Number } 8 \text { (August-2017) } \\
\text { Journal homepage: http://www.ijcrar.com }\end{array}$ & 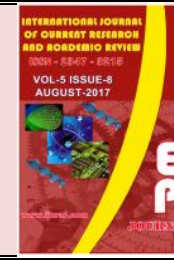 \\
\hline
\end{tabular}

doi: https://doi.org/10.20546/ijcrar.2017.508.012

\title{
Diagnosing the Undiagnosed ADHD Cases Using Vanderbilt Rating Scale
}

\author{
Aisha Begum* \\ Gowthamapuram, Ulsoor, Bangalore 560008, Karnataka, India \\ *Corresponding author
}

\begin{abstract}
The American Psychiatric Association (2000) defined Attention Deficit Hyperactive Disorder as a persistent pattern of inattention and/or hyperactivity - impulsivity that is more frequently displayed or more severe, than is typically observed in individuals at a comparable level of development. The aim of the study was to identify and estimate the undiagnosed cases of ADHD in school children and to create awareness about it amongst teachers and parents through an awareness program for appropriate referrals. The study was conducted on 110 children in the age group of 6-10yrs at schools of Bengaluru city based on the selection criteria. Data was collected using Vanderbilt ADHD Parent and teacher rating scales. The scores were tabulated and subjected to statistical analysis using McNamara test. Children with high risk of ADHD were identified. An awareness program was conducted to educate Parents and teachers about the simple home and school intervention strategies and to motivate them for appropriate referrals which would help in early medical intervention. Results revealed ADHD subtypes had significant behavioral and academic differences. $16.36 \%$ of children showed high risk for ADHD, out of which $10 \%$ were predominantly Attention deficit, $5.45 \%$ combination subtype and $0.91 \%$ predominantly hyperactive.
\end{abstract}

\section{Article Info}

Accepted: 30 July 2017

Available Online: 20 August 2017

\section{Keywords}

ADHD,

Vanderbilt rating scale,

School age children

\section{Introduction}

Attention Deficit Hyperactivity Disorder is one of the most prevalent chronic health conditions affecting school-aged children. (George J. Du Paul 2007)

It is characterized by developmentally inappropriate levels of attention and/or hyperactivity impulsivity.

Estimates of ADHD across the world, range from 2.2 to 17.8 percent. [Alikor E A D et al., 2015] In India, research on this disorder is in its nascent stage and initial epidemiological studies indicate that prevalence rate varies from 5-10 percent of the general population. [Abed M 2014]
Children with ADHD face many challenges in their everyday learning and self-worth perception and thus they are in need of support in several aspects throughout their lives. The three subtypes include the predominantly inattentive type, the predominantly hyperactiveimpulsive type and the combined type. [Skounti $\mathrm{M}$ et al., 2007]. The symptoms have considerable negative effects on the child's social, emotional and cognitive development which in turn affects the overall health and development of the child. For example, a child frequently faces low levels of self-esteem, as well as frustration and depression. [Malhi P, Singhi P 2000] These children are challenged in classroom settings yet are undiagnosed and unlikely to receive any formal or consistent intervention. 
There are various reasons why ADHD remains undiagnosed:

[www.addiss.co.uk/payingenoughattention]

- Too few pediatricians with an interest in mental health (85\%),

- General Practitioners are unsure of which patients to refer $(57 \%)$,

- Parents are not aware of ADHD (53\%),

- Fear of being branded a failure or blamed,

- Teachers are not aware and therefore do not realize that children should be referred to a medical professional.

Inspite of high ADHD prevalence, it is the most neglected and undiagnosed neurobehavioral condition.

Pediatric dentist is in a strategic position to interact with the child and observe him/her more closely than any other health care professional. ADHD children are very difficult to manage in a dental setup because of their inattention and hyperactivity. Hence, Pedodontist can play a very important role in identifying such subjects.

Hence, this research was undertaken for the purpose of identification and early intervention of overlooked cases that are experiencing mild levels of ADHD.

Aims and Objectives: To identify and estimate the undiagnosed cases of ADHD and to create awareness about it amongst teachers and parents by educating them about simple intervention strategies and motivating for appropriate referrals.

Source of Data: The study was conducted on 110 school children in the age group of 6-10yrs (Grade 1-4) of both genders at Bengaluru city.

Children who were not diagnosed with a pervasive developmental or psychotic disorder and Students receiving their education in the regular classroom setting were included in the study.

Children diagnosed with ADHD and who were under treatment for the same were excluded from the study.

Methods of Data Collection: After obtaining permission from the school authorities, parental consent was obtained from 110 children who were willing to participate in the study. Questionnaire, which included Vanderbilt Attention Deficit/Hyperactivity Disorder
Parent Rating Scale and teacher rating scale, was distributed among the parents and teachers and scoring criteria was explained to them. This assessment included input from both school and home settings, depending on the child's behavior in the past 6 months.

The scores were evaluated based on the ratings.

Vanderbilt Attention Deficit/Hyperactivity Disorder Parent Rating Scale and teacher rating scale has two versions: a parent form and a teacher form. [Mark L. Wolraich2002]

Both parent and teacher assessment scales have two components:

1. Symptom assessment - questions 1-18, which includes questions 1-9 pertaining to inattention and questions from 10-18 pertaining to hyperactivity with scoring options of never, occasionally, often and very often $(0,1,2,3$ respectively).

2. Impairment in performance- a set of question which include overall school performance i.e., reading, writing, mathematics, classroom behavior performance and relationship with parents, siblings, peers and team with scoring options of excellent, above average, average, somewhat of a problem and problematic $(1,2,3,4,5$ respectively).

Both Parent and teacher versions were assessed separately based on following standards:

- Predominantly inattentive type: Must score either a 2 or 3 on six or more items in questions 1-9, and score problematic on any one or two items in the performance section.

- Predominantly hyperactive/impulsive type: Must score either a 2 or 3 on six or more items in questions 10-18, and score problematic on any one or two items in the performance section.

- ADHD combined type: Meets criteria for both inattentive type and hyperactive/impulsive type.

To consider the child to be affected by ADHD, symptoms should be present in more than 1 setting i.e., both parents and teachers should be in complete agreement of the symptoms.

Either parent or teacher ratings alone cannot be considered as diagnostic. 
Children with high scores were noted and parents were counseled for further intervention.

Awareness program was conducted to educate Parents and teachers about simple home and school intervention strategies which included: [www.nasponline.org\&Brock S E et al., 2004]

- Instructional strategies to improve self-management;

- Contingency management- positive reinforcement, timeouts etc ;

- Collaboration and consultation with families to ensure that parental support for each child is fully utilized, to facilitate parental behavior support at home and to promote the use of consistent approaches across home, school and community settings;

- Classroom modifications to enhance work quality and productivity, engagement, and social adjustment;

- Education of school staff in characteristics and management of ADHD and attention problems to enhance appropriate instructional accommodations.

- Finally, referrals for psychiatric assistance.

\section{Results and Discussion}

The study was conducted on 110 subjects, which included 61 boys and 49 girls in the age group of 6-10 years.

Graph 1 depicts frequency and prevalence of ADHD which shows parent, teacher and combined parents and teacher rating. The diagnostic combined parent and teacher ratings reveal that 18 children (16.36\%) among the 110 subjects were found to meet the Vanderbilt Attention Deficit/Hyperactivity Disorder Parent \& teacher Ratings for ADHD.

Amongst them 11 were predominantly Attention Deficit, 1 was predominantly Hyperactive and 6 were combined Attention Deficit Hyperactive Disorder.

Table 1 shows the agreement between the parent and teacher ratings. There was statistically significant difference when parent and teacher rating were compared in the $\mathrm{AD}$ group, which showed Teacher ratings to be higher than parent ratings. However, there was an agreement between parents and teachers in HD and ADHD groups with no statistical significant difference. Tables 2 and 3 showing the comparison of parent and teacher ratings for different age groups and gender.
There was no statistical significant difference between Parent and teacher ratings with age and gender. Hence, it showed that ADHD was equally distributed in different age groups and in both boys and girls.

\section{The AAP guideline for the identification/diagnosis of ADHD recommends}

Vanderbilt Attention Deficit/Hyperactivity Disorder Parent Rating Scale (VADPRS), which utilizes information based on the Diagnostic and Statistical Manual of Mental Disorders, 4th Ed. (DSM-IV). [Laurel K. Leslie 2002] While the VADPRS has strong psychometric properties for the assessment of ADHD and is frequently used by physicians [ Becker S Pet al., 2012] The VADPRS is a parent-report scale with good internal consistency, factor structure, and concurrent validity for the assessment of ADHD. The VADPRS was created to collect uniform patient data and minimize the time burden of lengthy interviews. The internal consistency and factor structure of the VADPRS are a reliable, cost-effective assessment for ADHD in clinical and research settings. Hence, it was considered as the choice of diagnosis.[Wolraich M L et al., 2003]

The Vanderbilt rating scale performance items should be used with an interview about school functioning and a review of school records to rule out the presence of a comorbid reading or spelling Learning difficulties for children with diagnosed ADHD.[M. Langberg et al., 2010]

In the present study, 18 children $(16.36 \%)$ were found to meet the Vanderbilt Attention Deficit/Hyperactivity Disorder Parent \& teacher Rating Scale (VADPRS) for ADHD which was in accordance with Prevalence estimates between $2 \%-17 \%$ based on a behavioral definition which assesses symptoms stated by several studies. [Bhatia MS et al., 1991, Scahill L et al., 1999]

Among these 18 children, the inattention subtype was predominant, similar results were also reported by Mukhopadhyay M et al., in 2003. It may be because as a child reaches elementary school, the symptom of inattention may become more prominent and cause the child to struggle academically. [ NIMH Publication 2012] There was no statistical significant difference seen when scores of Teacher \& parent ratings with gender were analyzed, similar findings were observed by George $\mathrm{J}$ et al., where they concluded that both boys and girls with ADHD experience significant difficulties in school settings and impairment across the important 
domains of academic, social, emotional and behavioral functioning.[George J. DuPaul et al.,2006]But, unlike J A Venkata and A S Panicker'sstudy, which showed significant difference in the prevalence of ADHD between the males and the females, the ratio being 3:1.in addition, theyobserved that Teacher rating was higher than parent rating which was similar to the present study.
This may be due to the fact that children spend a greater time in the school and the teachers may observe the children's behavior more intensely and parents may fail to identify the presence of ADHD in their children due to lack of awareness about the symptoms of ADHD. [Venkata J A, PanickerA S2013]

Table.1 Agreement between Parents \& teachers rating for AD, HD and ADHD

\begin{tabular}{|c|c|c|c|c|c|}
\hline \multicolumn{6}{|c|}{ Agreement between Parents \& teachers rating for AD } \\
\hline & & \multicolumn{3}{|c|}{ Teacher AD } & \multirow{2}{*}{$\begin{array}{l}\text { P value } \\
\text { (McNemara test) }\end{array}$} \\
\hline & & Yes & No & Total & \\
\hline \multirow[t]{3}{*}{ Parent AD } & Yes & 11 & 0 & 11 & \multirow{3}{*}{$\begin{array}{l}\mathrm{p}<0.0001 \\
\text { (Significant) }\end{array}$} \\
\hline & No & 20 & 79 & 99 & \\
\hline & Total & 31 & 79 & 110 & \\
\hline \multicolumn{6}{|c|}{ Agreement between Parents \& teachers rating for $\mathrm{HD}$} \\
\hline & & \multicolumn{3}{|c|}{ Teacher HD } & \multirow{5}{*}{$\begin{array}{l}\mathrm{p}=0.125 \\
\text { (Not Significant) }\end{array}$} \\
\hline & & Yes & No & Total & \\
\hline \multirow[t]{3}{*}{ Parent HD } & Yes & 1 & 0 & 1 & \\
\hline & No & 4 & 105 & 109 & \\
\hline & Total & 5 & 105 & 110 & \\
\hline \multicolumn{6}{|c|}{ Agreement between Parents \& teachers rating for ADHD } \\
\hline & & \multicolumn{3}{|c|}{ Teacher ADHD } & \multirow{5}{*}{$\begin{array}{l}\mathrm{p}=1.00 \\
\text { (Not Significant) }\end{array}$} \\
\hline & & Yes & No & Total & \\
\hline \multirow{3}{*}{$\begin{array}{l}\text { Parent } \\
\text { ADHD }\end{array}$} & Yes & 6 & 1 & 7 & \\
\hline & No & 1 & 102 & 103 & \\
\hline & Total & 7 & 103 & 110 & \\
\hline
\end{tabular}

Table.2 Comparison of parent and teacher ratings with age group

\begin{tabular}{|c|c|c|c|c|}
\hline \multirow[b]{2}{*}{ Age } & \multicolumn{2}{|l|}{ AD only } & \multirow[b]{2}{*}{ Total } & \multirow[t]{2}{*}{$\mathrm{p}$ value } \\
\hline & Yes & No & & \\
\hline 6 Years & $1(3.85)$ & $25(96.15)$ & $26(100)$ & \multirow{5}{*}{$\begin{array}{l}\mathrm{p}=0.204 \\
\text { (Not Significant) }\end{array}$} \\
\hline 7 Years & $3(8.11)$ & $34(91.89)$ & $37(100)$ & \\
\hline 8 Years & $6(20.69)$ & $23(79.31)$ & $29(100)$ & \\
\hline 9 Years & $1(5.56)$ & $17(94.44)$ & $18(100)$ & \\
\hline Total & $11(10)$ & $99(90)$ & $110(100)$ & \\
\hline \multirow[b]{2}{*}{ Age } & \multicolumn{2}{|l|}{ HD only } & \multirow[b]{2}{*}{ Total } & \multirow{2}{*}{$\mathrm{p}$ value } \\
\hline & Yes & No & & \\
\hline 6 Years & $1(3.85)$ & $25(96.15)$ & $26(100)$ & \multirow{5}{*}{$\begin{array}{l}\mathrm{p}=0.400 \\
\text { (Not Significant) }\end{array}$} \\
\hline 7 Years & $0(0)$ & $37(100)$ & 37 (100) & \\
\hline 8 Years & $0(0)$ & $29(100)$ & $29(100)$ & \\
\hline 9 Years & $0(0)$ & $18(100)$ & $18(100)$ & \\
\hline Total & $1(0.91)$ & $109(99.09)$ & $110(100)$ & \\
\hline \multirow[b]{2}{*}{ Age } & \multicolumn{2}{|c|}{ ADHD combined } & \multirow{2}{*}{ Total } & \multirow{2}{*}{$\mathrm{p}$ value } \\
\hline & Yes & No & & \\
\hline 6 Years & $2(7.69)$ & $24(92.31)$ & $26(100)$ & \multirow{5}{*}{$\begin{array}{l}p=0.419 \\
\text { (Not Significant) }\end{array}$} \\
\hline 7 Years & $1(2.7)$ & $36(97.3)$ & $37(100)$ & \\
\hline 8 Years & $3(10.34)$ & $26(89.66)$ & $29(100)$ & \\
\hline 9 Years & $0(0)$ & $18(100)$ & $18(100)$ & \\
\hline Total & $6(5.45)$ & $104(94.55)$ & $110(100)$ & \\
\hline
\end{tabular}


Table.3 Comparison of Parent and Teacher ratings with gender

\begin{tabular}{|c|c|c|c|c|}
\hline & \multicolumn{2}{|l|}{ AD only } & & \multirow[t]{2}{*}{$\mathrm{p}$ value } \\
\hline & Yes & No & Total & \\
\hline Male & $9(14.75)$ & $52(85.25)$ & $61(100)$ & \multirow[t]{3}{*}{$\mathrm{p}=0.107$} \\
\hline Female & $2(4.08)$ & $47(95.92)$ & $49(100)$ & \\
\hline \multirow[t]{4}{*}{ Total } & $11(10)$ & $99(90)$ & $110(100)$ & \\
\hline & \multirow{2}{*}{\multicolumn{2}{|c|}{ HD only }} & & \multirow{3}{*}{$\mathrm{p}$ value } \\
\hline & & & & \\
\hline & Yes & No & Total & \\
\hline Male & $0(0)$ & $61(100)$ & $61(100)$ & \multirow[t]{3}{*}{$\mathrm{p}=0.445$} \\
\hline Female & $1(2.04)$ & $48(97.96)$ & $49(100)$ & \\
\hline \multirow[t]{3}{*}{ Total } & $1(0.91)$ & $109(99.09)$ & $110(100)$ & \\
\hline & \multicolumn{2}{|c|}{ ADHD Combined } & & \multirow{2}{*}{$\mathrm{p}$ value } \\
\hline & Yes & No & Total & \\
\hline Male & $3(4.92)$ & $58(95.08)$ & $61(100)$ & \multirow[t]{3}{*}{$\mathrm{p}=0.999$} \\
\hline Female & $3(6.12)$ & $46(93.88)$ & 49 (100) & \\
\hline Total & $6(5.45)$ & $104(94.55)$ & $110(100)$ & \\
\hline
\end{tabular}

Graph.1 Frequency \& Prevalence of ADHD $(n=110)$



Early intervention research also suggests that simpler and less intensive interventions may be required for children who are identified early rather than the more intensive programmes that may be required if problem is well established in middle childhood. [Edmund J. S. SonugaBarke et al., 2006] similarly in the present study after an awareness programme on school and home interventions, there was marked improvement seen in the performance of the children and was highly appreciated by teachers and parents.

Schools and teachers play significant role in identifying and providing appropriate intervention for ADHD children and has proved to be more helpful than other interventions as Parents are more likely to respond to academic concerns rather than other behavioral concerns of the child. [Edmund J. S. Sonuga-Barke et al., 2006]

Schools play important roles in the psychosocial development of the child as they constitute frames where developmental domains engage and transform (Noam \& Hermann, 2002). Studies suggesting parent preferences for educational interventions over psychiatric interventions for ADHD coupled with stigma associated in accessing psychiatric services strongly indicated the need for research that would help mental health 
professionals restructure information and early intervention paradigms about ADHD within a school context.

Limitation of the study: This rating scale alone cannot be considered for the diagnosis of ADHD further psychiatric clinical assessment is required for the final diagnosis and studies on larger population is needed.

Attention Deficit Hyperactivity Disorder (ADHD) is the most common neurobehavioral disorder in school aged children and at times associated with the development of anti-social personality as co-morbid conditions. Early identification and intervention of this multi factorial neuro-psychiatric condition in the children will help them improve their academic performance and prevent the development of co-morbid conditions.

Pediatric dentists will face great deal of difficulties to provide access to the oral health care system and establishing a treatment plan for those with unique medical, behavioral and dental needs. Dental professionals caring for patients with ADHD must exhibit compassion and must not misinterpret a patient's inattention, hyperactivity or impulsivity as a sign of defiance, but as a manifestation of the disease.

Hence, Pediatric dentist should be well informed about symptoms and should be prepared to identify children with the disorder with thorough knowledge of health history/medication implications, recognition of possible oral presentations and flexibility in adjusting the treatment plan.

\section{References}

Abed M 2014, Current Understanding of ADHD.A Critical Review.NewYork Science Journal 7(6): 4959

ADHD: PAYING ENOUGH ATTENTION? a research report investigating ADHD in the UK. www.addiss.co.uk/payingenoughattentin

Alikor E A D, Briggs A I F, Okoh B A NMarch 2015, Attention Deficit Hyperactivity Disorder Among School Children in Port Harcourt, Nigeria American Journal of Psychiatry and Neuroscience 3(2): 23-29

Attention Deficit Hyperactivity Disorder. NIMH Information and Publications.U.S. Department of Health and Human Services national institutes of Health. NIMH publication no. 12-3572 revised 2012
Becker S P, Langberg J M, Vaughn A J, Epstein J N2012 Apr, .Clinical Utility of the Vanderbilt ADHD Diagnostic Parent Rating Scale Comorbidity Screening Scales.J DevBehav Pediatric 33(3): 221228.

Bhatia MS, Nigam VR, Bohra N, Malik SC 1991, Attention deficit disorder with hyperactivity among pediatric outpatients. J Child Psychol Psychiatry 32: 297-306.

Brock S E, Grove B \&Searls M 2004, ADHD classroom interventions. Helping children at home and school II: Handouts for families and educators. National association of school psychologists.

Edmund J. S. Sonuga-Barke, Thompson M, Abikoff H, Klein R, Brotman L M 2006,Nonpharmacological Interventions for Preschoolers With ADHD The Case for Specialized Parent Training. Infants \& Young Children 19(2): 142-153

George J. DuPaul 2007, School-Based Interventions for Students with Attention Deficit Hyperactivity Disorder: Current Status and Future Directions. School Psychology Review, 36(2): 183-194

George J. DuPaul, AshaK. Jitendra, Katy E. Tresco, Rosemary E. Vile Junod Robert J. Volpe J. Gary Lutz 2006, Children With Attention Deficit Hyperactivity Disorder:Are There Gender Differences in School Functioning? School Psychology Review, 35(2): 292-308

Laurel K. Leslie 2002 Aug, The Role of Primary Care Physicians in Attention Deficit Hyperactivity Disorder (ADHD)Pediatr Ann. 31(8): 475-484.

M. Langberg, Vaughn A J, Brinkman W B, Froehlich T, Epstein J N November 2010, Clinical Utility of the Vanderbilt ADHD Rating Scale for Ruling Out Comorbid Learning Disorders. Journal of Pediatrics 126(5).doi: 10.1542/peds.2010-1267

Malhi P, Singhi P 2000, Spectrum of Attention Deficit Hyperactivity Disorders in Children Among Referrals to Psychology Services Indian Pediatrics volume 37: 1256-1260

Mark L. Wolraich 2002, NICHQ Vanderbilt assessment scale. Used for diagnosing ADHD. American Academy of Pediatrics and National Initiative for Children's Healthcare Quality Revised - 0303, Pp 11-21

Mukhopadhyay M, Misra S, Mitra T, Niyogi P2003 Oct,Attention deficit hyperactivity disorder. Indian J Pediatr. 70(10):789-92.

NASP Position Statement: Students With Attention Deficit Hyperactivity Disorder (awareness programme)

https://www.nasponline.org/x26833.xml 
Noam G G\& Hermann C A 2002, where education and mental health meet: Developmental prevention and early interventions in schools.Development and psychopathology, 14, 861-875. [Cross ref, Google scholar]

Scahill L, Schwab-Stone M, Merikangas KR, Leckmaz JF, Zhang H, Kasl S 1999, Psychosocial and clinical correlates of ADHD in a community sample of school-age children. J Am Acad Child Adolesc Psychiatry, 38:976-84.

Skounti M, Philalithis A, Galanakis E2007 Feb, Variations in prevalence of attention deficit hyperactivity disorder worldwide. Eur J Pediatr. 166(2):117-23.

Venkata J A, Panicker A S2013, Prevalence of attention deficit hyperactivity disorder in primary school children. Indian journal of psychiatry 55(4): 338342

Wolraich M L, Lambert W, Doffing M A, Bickman L, Simmons T, and Worley K 1 December 2003,Psychometric Properties of the Vanderbilt ADHD Diagnostic Parent Rating Scale in a Referred Population. Journal of Pediatric Psychology 28(8): 559-568.

How to cite this article:

Aisha Begum. 2017. Diagnosing the Undiagnosed ADHD Cases Using Vanderbilt Rating Scale. Int.J.Curr.Res.Aca.Rev. 5(8), 81-87. doi: https://doi.org/10.20546/ijcrar.2017.508.012 